\title{
IS PSEUDOEXFOLIATION A SIGNIFICANT RISK FACTOR FOR GLAUCOMA? A CROSS-SECTIONAL ANALYSIS OF A PAKISTANI POPULATION
}

\author{
Abdul Rauf, Hussnain Abbas, Saqib Ali*, Haroon Javaid, Khalid Naimat \\ Combined Military Hospital, Multan/National University of Medical Sciences (NUMS) Pakistan, *Combined Military Hospital, Sargodha/National University of \\ Medical Sciences (NUMS) Pakistan
}

\section{ABSTRACT}

Objective: To determine the association between pseudoexfoliation and glaucoma.

Study Design: Cross-sectional analytical study.

Place and Duration of Study: Eye Outpatient department of Combined Military Hospital, Multan from Jan to Dec 2019.

Methodology: A total of 170 patients reporting to the eye outpatient department were examined for the presence of Pseudoexfoliation and glaucoma based on raised intraocular pressure $>21 \mathrm{~mm} \mathrm{Hg}$, increased cup disc ratio and visual field defects. Therefore, a total of 340 eyes were examined.

Results: Out of a total of 252 eyes with pseudoexfoliation, $40(15.9 \%)$ had glaucoma. This frequency of glaucoma was significantly higher in eyes with pseudoexfoliation 87 (98.9\%), in comparison to eyes without pseudoexfoliation 1 (1.1\%); $p<0.01)$.

Conclusion: Pseudoexfoliation was found to be strongly associated with glaucoma.

Keywords: Glaucoma, Pseudoexfoliation, Pseudoexfoliation syndrome.

This is an Open Access article distributed under the terms of the Creative Commons Attribution License (https://creativecommons.org/licenses/by-nc/4.0/), which permits unrestricted use, distribution, and reproduction in any medium, provided the original work is properly cited.

\section{INTRODUCTION}

Glaucoma has an estimated prevalence of about $3.5 \%$ globally 1 . It is a group of eye conditions which tend to increase the ocular pressure leading to damage of the optic nerve. The health of the optic nerve is essential in order to have a good vision. About $10 \%$ of these people suffer from bilateral blindness and glaucoma is also believed to be the leading cause of irreversible blindness. Patients with glaucoma may remain asymptomatic until it reaches a severestage ${ }^{1}$. That is why, most patients who get blind due to glaucoma are over the age of 60 years. Also, since a large proportion of glaucoma patients remain asymptomatic, it may be safe to assume that the prevalence of glaucoma is much higher than reported ${ }^{2}$.

Several risk factors have been reported to be associated with glaucoma, such as old age, familial predilection, race and prolonged use of systemic or topical corticosteroids ${ }^{1}$. Gender is another risk factor, with females being more prone to suffer from glaucoma as compared to men ${ }^{3}$. According to Tham et al, the number of people suffering from glaucoma is predicted to increase from 64.3 million in 2013 to 111.8 million in $2040^{4}$. It is also possible that infants and children are found to have glaucoma from birth or in first few years of their life. Such children should be investigated for any blockage of drainage ducts or any other under-

Correspondence: Dr Abdul Rauf, Classified Eye Specialist, Combined Military Hospital, Multan Pakistan

Received: 22 Apr 2020; revised received: 04 Aug 2020; accepted: 31 Aug 2020 lying systemic cause.

Glaucoma comprises of a group of neurodegenerative disorders involving the apoptosis of the retinal ganglion cells (RGCs) ${ }^{5}$. These cell axons exit the eye through the lamina cribrosa (LC), forming the optic nerve, and divide into left and right lateral geniculate nucleus which are the thalamic relay nuclei for vision'. The level of intraocular pressure is mainly believed to be responsible for retinal ganglion cell death. Intraocular pressure (IOP) is the balance between the secretion of aqueous humor by ciliary body and its drainage through the trabecular meshwork and uveoscleral outflow pathway ${ }^{6,7}$. With the elevated IOP, the lamina cribrosa is thinned and pushed posteriorly leading to a deep cupping (characteristic appearance of optic nerve) and narrowing of the neuroretinal rim. If the IOP increases beyond a certain point $(21 \mathrm{mHg})$, the retinal ganglion cells start to degenerate ${ }^{6,7}$. The resulting atrophy of the optic nerve damages the visual field thus causing gradual irreversible vision loss ${ }^{8}$. It is also possible that the optic nerve gets damaged although the intraocular pressure is found to be in a normal range. The reason for such a condition is still unknown. But according to some theories, buildup of fatty deposits (atherosclerosis) in the arteries supplying the eye can limit the blood supply to the optic nerve causing its continued degeneration 8 .

Many local and systemic conditions are found to co-exist with glaucoma. However, relationship of association of some symptoms has not been investigated by many researchers. The above-mentioned characteristic 
elastosis of the optic nerve has also been demonstrated in patients with pseudoexfoliation. Previous studies have shown that people with elevated intraocular pressure also have pseudoexfoliation ${ }^{8,9}$.

Many suggest that nearly $50 \%$ of the patients with pseudoexfoliation develop glaucoma. However, there is lack of evidence and no such study has been carried out in Pakistan to quantify the association of the two diseases. This objective of this study was to assess the relationship between the presence of glaucoma and pseudoexfoliation in a Pakistani population.

\section{METHODOLOGY}

A cross-sectional analytical study was conducted in Combined Military Hospital, Multan, from January till December 2019. The WHO sample size calculator was used for estimating the sample size. Data from Micthel et al,'s Blue Mountain study was taken for sample size estimation. Mitchel et al, reported glaucoma prevalence of $14.2 \%$ in patients with pseudoexfoliation and $1.7 \%$ in eyes without pseudoexfoliation ${ }^{10}$. In order to calculate this difference with a significance level of $5 \%$ and a power of $99 \%$, a sample size of 168 eyes was estimated. We recruited 170 patients in the present study having a total of 340 eyes in our study sample.

A total of 170 patients were recruited by nonprobability, consecutivesampling technique. Patients who presented to the Ophthalmology Outpatient department (OPD) with a complaint of blurred vision were requested to participate in the study. Those patients who gave informed consent were recruited in the study. Ethics approval for this study was taken from the $\mathrm{CMH}$ ethical review committee. A detailed medical history was recorded from all potential participants. Patients with any systemic disease such as diabetes mellitusor any cardiovascular disorders were excluded from the study.

In order to assess pseudoexfoliation, pupils of all patients were dilated. After pupillary dilation was achieved, a high-magnification assessment of the anterior chamber of the eye was done using a narrowslit beam. A left-to-right thorough examination of each lens was done to specifically record any changes characteristic of pseudoexfoliation, such as radial lines or granular deposits. A final diagnosis of pseudoexfoliation was determined by the presence of white layered deposition on the anterior aspect of the lens. Patients having cataract hampering visual field examination were excluded.
The diagnosis of glaucoma was based on the assessment of IOP $>21 \mathrm{~mm}$ of $\mathrm{Hg}$, increased cup disc ratio and visual field defects. All data was entered and analyzed using SPSS 25. Frequencies and percentages were described for gender, pseudoexfoliation, and the presence of glaucoma. Mean and standard deviation was described for age. Any association in the frequency distribution of pseudoexfoliation between patients with and without glaucoma was determined by applying Fisher's exact test. The mean intraocular pressure between the right and left eyes was compared using Independent samples t-test. The relative risk of having developing glaucoma in patients with psudoexfoliation, as compared to patients without psudoexfoliation was also calculated.

\section{RESULTS}

A total of 170 patients were recruited in study. The mean age of the participants was $65.46 \pm 8.89$ years. Out of these, there were $82(48.2 \%)$ males and 88 $(51.8 \%)$ females. Since each patient had a pair of eyes, the total number of eyes examined were 340 . Out of the 340 eyes examined, a total of 41 eyes (12.1\%) had glaucoma, while 299 eyes (87.9\%) were without any glaucoma. Glaucoma was found to be equally distributed across the two genders (table-I).

Among the 41 eyes that had glaucoma, 20 (48.8\%) were on the right side, while there were 21 (51.2\%) left eyes. Thus, the distribution of glaucoma was also found to be equally distributed between the right and left eyes (table-II).

Table-I: Glaucoma distribution across the two genders.

\begin{tabular}{l|c|c|c}
\hline & $\begin{array}{c}\text { Glaucoma } \\
\text { Present }\end{array}$ & $\begin{array}{c}\text { Glaucoma } \\
\text { Absent }\end{array}$ & $\boldsymbol{p}$-value \\
\hline Females & $15(9.1 \%)$ & $149(90.9 \%)$ & \multirow{2}{*}{0.11} \\
\hline Males & $26(14.8 \%)$ & $150(85.2 \%)$ & \\
\hline
\end{tabular}

Table-II: Frequency distribution of glaucoma in both eyes $(\mathrm{n}=340)$.

\begin{tabular}{l|c|c|c}
\hline & $\begin{array}{c}\text { Glaucoma } \\
\text { Present }\end{array}$ & $\begin{array}{c}\text { Glaucoma } \\
\text { Absent }\end{array}$ & \multirow{2}{*}{-value } \\
\hline Right Eye & $20(48.8 \%)$ & $150(50.2 \%)$ & \multirow{2}{*}{0.87} \\
\hline Left Eye & $21(51.2 \%)$ & $149(49.8 \%)$ & \\
\hline
\end{tabular}

The overall mean intraocular pressure was found to be $14.95 \pm 4.61 \mathrm{~mm} \mathrm{Hg}$. There was no difference in the intraocular pressure in the right eyes $(14.96 \pm 4.85$ $\mathrm{mmHg}$ ), as compared to the pressure in the left eyes (14.94 $\pm 4.38 \mathrm{mmHg} ;=0.97)$.

The association between pseudoexfoliation and glaucoma was assessed using Fisher's exact test. The distribution of glaucoma in patients having pseudoexfoliation has been illustrated in table-II. Out of the 
252 eyes with pseudoexfoliation, only 40 (15.9\%) had glaucoma. In comparison, among the 88 eyes without pseudoexfoliation, only 1 (1.1\%) eye reported as having glaucoma (table-III). Furthermore, the relative risk ratio analysis revealed that patients with Pseudoexfoliation were 11.93 (95\% Confidence intervals 1.7183.35) more likely to develop glaucoma, in comparison to the patients that did not have any exfoliation.

Table-III: Frequency distribution of glaucoma in patients with pseudoexfoliation $(n=340)$.

\begin{tabular}{|c|c|c|c|c|}
\hline & $\begin{array}{c}\text { Pseudo- } \\
\text { exfoliation } \\
\text { Present }\end{array}$ & $\begin{array}{c}\text { Pseudo- } \\
\text { exfoliation } \\
\text { Absent }\end{array}$ & $\begin{array}{c}p- \\
\text { value }\end{array}$ & $\begin{array}{c}\text { Relative } \\
\text { Risk; } \\
\text { 95\% CI }\end{array}$ \\
\hline $\begin{array}{l}\text { Glaucoma } \\
\text { Present }\end{array}$ & $40(15.9 \%)$ & $1(1.1 \%)$ & \multirow{2}{*}{$<0.01$} & \multirow{2}{*}{$\begin{array}{l}11.93 \\
(1.71- \\
83.35)\end{array}$} \\
\hline $\begin{array}{l}\text { Glaucoma } \\
\text { Absent }\end{array}$ & $212(84.1)$ & 87 (98.9\%) & & \\
\hline
\end{tabular}

\section{DISCUSSION}

This study assessed 170 participants for the presence of glaucoma in patients with and without pseudoexfoliation in their right and left eyes $(n=340)$.

The condition is termed so because it not actual exfoliation of the eye but deposited material gives a false picture of exfoliation. The material is insoluble and floats in the aqueous humor. John Lindberg of Finland described it as lens exfoliation in 1917. Later on, Dr. Georgiana Dvorak Theobald, who was a famous pathologist, changed its name to pseudoexfoliation to distinguish it from the 'true' exfoliative condition which occurs in the glass blowers who work without using eye protection shields ${ }^{11}$.

Pseudoexfoliation, also referred to as the exfoliation syndrome, is the deposition of whitish-gray fibrillar, protein-like material within the anterior segment of the eye including the iris, lens, ciliary epithelium, cornea and trabecular meshwork ${ }^{12}$. The pathological reports reveal that this material is microscopic granular amyloid-like protein fiber. If the eye is examined through the slit-lamp, the movements of the pupil push these deposits centrally in a classic 'bull's eye' pattern ${ }^{13}$.

The pseudoexfoliative material can block or decrease the aqueous humor outflow escalating the intraocular pressure ${ }^{14,15}$. Presence of pseudoexfoliative material on the ocular tissue itself puts the optic nerve in danger of being damaged progressively. Pseudoexfoliation like glaucoma is more prevalent in female as compared to males. Other contributing factors include old-age, environmental factors such as dust and pollution of industries and genetics. The LOXL1 gene was found in almost all the patients presenting with pseudoexfoliation in Scandinavian and Bantu population ${ }^{16}$.

A number studies have attempted to establish the role of pseudoexfoliation as the risk factor of glauco$\mathrm{ma}^{15,17,18}$. On the other hand, literature also debates that the existence of pseudoexfoliation and glaucoma in a single patient is merely coincidental ${ }^{6}$.

The present study reported a strong association between glaucoma and pseudoexfoliation $(p<0.01)$. Out of the 252 eyes having pseudoexfoliation, 40 (15.9\%) were reported to have glaucoma. Among the 88 eyes without any pseudoexfoliation, only one $(1.1 \%)$ had glaucoma. Cashwell et al. reported a 10\% incidence of glaucoma in people with pseudoexfoliation in an American cohort ${ }^{19}$. Mitchell et al, in a similar study conducted by examining almost 7000 eyes reported similar results. Out of 120 eyes with pseudoexfoliation, $17(14.2 \%)$ had glaucoma. Only 119 (1.7\%) eyes had glaucoma out of a total of 6847 eyes without pseudoexfoliation ${ }^{10}$. On the contrary in the present study, 212 eyes $(84.1 \%)$ out of a total of 252 eyeshad pseudoexfoliation but glaucoma was not present. Thus, the study showed that it is not necessary for the patient with pseudoexfoliation to have glaucoma at the same time. The findings differ froma study of an Australian population wherethe risk for glaucoma from pseudoexfoliation was only $2.7 \%{ }^{10}$.

The present study reported that patients having Pseudoexfoliation were almost 12 times more like to develop glaucoma, when compared to individuals that did not have any Pseudoexfoliation. On a comparative note, the Thessaloniki Eye study showed that subjects with pseudoexfoliation were three times more prone to develop glaucoma than patients who had no pseudoexfoliation. The proportion with glaucoma among pseudoexfoliative participants $(15.2 \%)$ was higher than that for glaucoma among non-pseudoexfoliative participants $(4.7 \%)^{14}$. The outcomes of our study are in match the findings of this research. These statistics suggest that pseudoexfoliation must be considered a highly significant risk factor when assessing patients for possible development of glaucoma. In addition, this also means that pseudoexfoliation is a risk factor for glaucomatous eye and the patients with pseudoexfoliationshould be treated once diagnosed to prevent progression of glaucoma.

The Pseudoexfoliation syndrome has been identified as one of the most significant risk factors responsible for the occurrence of secondary glaucoma also referred to as 'pseudoexfoliative glaucoma'. Topouzis 
et al, reported a prevalence of $11.9 \%$ for pseudoexfoliative glaucoma among an elderly Greek population ${ }^{20}$. Since the mean age of the participants in the present study was $65.46 \pm 8.89$ years, this population should also be considered as elderly. Interestingly, even in this elderly cohort of the population, $15 \%$ of patients with pseudoexfoliation had glaucoma. Thus, these findings match those of the study by Topouzis et al20.

The underlying biological reasoning as to why certain patients having glaucoma have pseudoexfoliation, while other do not is still not fully understood. Other studies have reported the presence of such pseudoexfoliative exudates in other organs, namely, the liver, kidneys, gall bladder and even in the cerebral meninges. This fact may be used to hypothesize an association between pseudoexfoliation in glaucoma patients with other systemic conditions of a cardiovascular or cerebrovascular origin ${ }^{21,22}$. Some experts opine that pseudoexfoliation may lead to an over-diagnosis of glaucoma due to the misinterpretation of clinical signs ${ }^{10}$. Since the distribution of glaucoma in the present study was equally distributed across both genders, this suggests that there is no gender predilection for glaucoma in our population. Also, no difference between right or left eyes was reported in the present study. This also suggests that a predilection of glaucoma was not found for either side. No such predilection has been reported in literature. Thus, our study corro-borates such findings.

Other risk factors such as systemic conditions are possible confounders that were not accounted for in this study. Future studies should include these risk factors for analysis.

\section{CONCLUSION}

This study suggests a strong association between pseudoexfoliation and the occurrence of glaucoma. However, the impact of other plausible risk factors was not studied. Future studies should focus on matching possible confounding variables at the baseline and take a larger sample of patients.

\section{CONFLICT OF INTEREST}

This study has no conflict of interest to be declared by any author.

\section{REFERENCES}

1. Quigley HA, Broman AT. The number of people with glaucoma worldwide in 2010 and 2020. Br J Ophthalmol 2006; 90(3): 262-67.

2. Gupta P, Zhao D. Prevalence of glaucoma in the United States: the 2005-2008 national health and nutrition examination survey. Invest Ophthalmol Vis Sci 2016; 57(6): 2905-13.
3. Joseph G, Thirunavukkarasu A. A study of prevalence and characteristics of glaucoma in pseudo exfoliation syndrome. Indian J Clin Exp Ophthalmol 2016; 2(4): 304-308.

4. Tham YC, Li X, Wong TY. Global prevalence of glaucoma and projections of glaucoma burden through 2040: a systematic review and meta-analysis. Ophthal-mol 2014; 121(11): 2081-90.

5. Weinreb RN, Leung CK, Crowston JG, Medeiros FA, Friedman DS, Wiggs JL, et al. Primary open-angle glaucoma. Nat Rev Dis Primers 2016; 2(1): 1-19.

6. Konstas AG, Ringvold A. Epidemiology of exfoliation syndrome. J Glaucoma 2018; 27(2): S4-S11.

7. Chatzikyriakidou A, Founti P, Melidou A, Minti F, Bouras E. Micro RNA-related polymorphisms in pseudoexfoliation syndrome, pseudoexfoliative glaucoma, and primary open-angle glaucoma. Ophthalmic Genet 2018; 39(5): 603-609.

8. Conlon R, Saheb H, Ahmed IIK. Glaucoma treatment trends: a review. Can J Ophthalmol 2017; 52(1): 114-24.

9. Ekström C. Elevated intraocular pressure and pseudoexfoliation of the lens capsule as risk factors for chronic open-angle glaucoma: A population based five year follow up study. Acta Ophthalmol 1993; 71(2): 189-95.

10. Mitchell P, Wang JJ, Hourihan F. The relationship between glaucoma and pseudoexfoliation: the Blue Mountains Eye Study. Arch Ophthalmol 1999; 117(10): 1319-24.

11. Chang DF, Osher RH, Wang L, Koch DD. Prospective multicenter evaluation of cataract surgery in patients taking tamsulosin (Flomax). Ophthalmol 2007; 114(5): 957-64.

12. Campbell RJ, El-Defrawy SR, Gill SS, Whitehead M, de LP Campbell E, Hooper PL, et al. Evolution in the risk of cataract surgical complications among patients exposed to tamsulosin: a population-based study. Ophthalmol 2019; 126(4): 490-96.

13. Grødum K. Risk of glaucoma in ocular hypertension with and without pseudoexfoliation. Ophthalmol 2005; 112(3): 386-90.

14. Anastasopoulos E, Coleman AL, Wilson MR, Sinsheimer JS, Yu F, Katafigiotis S, et al. Association of LOXL1 polymorphisms with pseudoexfoliation, glaucoma, intraocular pressure, and systemic diseases in a Greek population. The Thessaloniki eye study. Invest Ophthalmol Vis Sci 2014; 55(7): 4238-43.

15. Topouzis F, Founti P, Yu F, Wilson MR, Coleman AL. Twelveyear incidence and baseline risk factors for pseudoexfoliation: the Thessaloniki Eye Study (An American Ophthalmological Society Thesis). Am J Ophthalmol 2019; 206(1): 192-14.

16. Kasım B, İrkeç M, Alikaşifoğlu M, Orhan M, Mocan MC, Aktaş D. Association of LOXL1 gene polymorphisms with exfoliation syndrome/glaucoma and primary open angle glaucoma in a Turkish population. Mol Vis 2013; 19(1): 114-20.

17. Butt NH, Ayub MH. Challenges in the management of glaucoma in developing countries. Taiwan J Ophthalmol 2016; 6(3): 119-22.

18. Fechtner RD. Glaucoma in Developing Countries. Rev Optom 2018; 155(3): S19-S22.

19. Cashwell LF. Exfoliation syndrome prevalence in a Southeastern United States population. Arch Ophthalmol 1988; 106(3): 335-36.

20. Topouzis F, Wilson MR, Harris A, Anastasopoulos E, Yu F, Mavroudis L, et al. Prevalence of open-angle glaucoma in Greece: the Thessaloniki Eye Study. Am J ophthalmol 2007; 144(4): 511-19.

21. Dar N, Belkin A, Pillar S, Sheiman V, Tempelhof OF, Barkana Y, et al. Effects of Postural Variation on Intra-ocular Pressure: Comparison between Pseudo-exfoliation Glaucoma and Primary Open Angle Glaucoma. Curr Eye Res 2020: 45(10): 1-6.

22. Yildirim N, Yasar E, Gursoy H. Prevalence of pseudoexfoliation syndrome and its association with ocular and systemic diseases in Eskisehir, Turkey. Int J ophthalmol 2017; 10(1): 128-32. 